\title{
Легирование термоэлектрических материалов на основе твердых растворов SiGe в процессе их синтеза методом электроимпульсного плазменного спекания
}

\author{
(C) М.В. Дорохин ${ }^{1}$, П.Б. Демина ${ }^{1}$, И.В. Ерофреева ${ }^{1}$, А.В. Здоровейщев ${ }^{1}$, Ю.М. Кузнецов ${ }^{1}$, \\ M.C. Болдин ${ }^{1}$, А.А. Попов ${ }^{1}$, Е.А. Ланцев ${ }^{1}$, А.В. Боряков ${ }^{2}$ \\ ${ }^{1}$ Научно-исследовательский институт Нижегородского государственного университета им Н.И. Лобачевского, \\ 603950 Нижний Новгород, Россия \\ ${ }^{2}$ Нижегородский государственный университет им. Н.И. Лобачевского, \\ 603950 Нижний Новгород, Россия \\ E-mail: dorokhin@nifti.unn.ru
}

Поступила в Редакцию 24 апреля 2019 г.

В окончательной редакции 29 апреля 2019 г.

Принята к публикации 29 апреля 2019 г.

\begin{abstract}
Представлены результаты исследования термоэлектрических материалов, сформированных методом электроимпульсного плазменного спекания, и представляющих собой твердые растворы $\mathrm{Ge}_{x} \mathrm{Si}_{1-x}$, легированные атомами $\mathrm{Sb}$ до концентрации в пределах 0-5aт\%. Получено, что при концентрации $\mathrm{Sb}$ ниже $1 \mathrm{aT} \%$ осуществляется эффективное легирование твердого раствора в процессе спекания, которое позволяет сформировать термоэлектрический материал со сравнительно высоким коэффициентом термоэлектрической добротности. Повышение концентрации сурьмы в диапазоне 1-5ат\% приводит к изменению механизма легирования, результатом которого является повышение сопротивления материалов и собирания $\mathrm{Sb}$ в крупные кластеры. Для таких материалов отмечается существенное снижение коэффициента Зеебека и термоэлектрической добротности. Наибольшее полученное значение коэффициента термоэлектрической добротности ZT при легировании атомами $\mathrm{Sb}$ составило 0.32 при $350^{\circ} \mathrm{C}$, что сопоставимо с известными аналогами для твердого раствора $\mathrm{Ge}_{x} \mathrm{Si}_{1-x}$.
\end{abstract}

Ключевые слова: термоэлектричество, твердый раствор $\mathrm{Ge}_{x} \mathrm{Si}_{1-x}$, легирование, кластеры, $\mathrm{Sb}$, плазменное спекание.

DOI: 10.21883/FTP.2019.09.48121.04

\section{1. Введение}

В настоящее время в мире интенсивно развиваются физика и технология альтернативных источников электроэнергии, в частности, функционирующих на основе эффекта Зеебека - термоэлектрических преобразователей энергии. Такой вариант источников энергии является автономным, компактным, кроме того, работа термоэлектриков основана на разогреве, следовательно, они могут создавать электроэнергию на основе „бросового“ тепла, выделяющегося в результате технологических, эксплуатационных, бытовых процессов. Обзор [1] отражает современный уровень исследований в этом фундаментальном и одновременно очень важном прикладном направлении физики твердого тела.

Основным характеризующим параметром для термоэлектриков является безразмерный коэффициент термоэлектрической добротности ZT, который в свою очередь зависит от таких макропараметров, как коэффициент теплопроводности $\kappa$, электропроводность $\sigma$ (или удельное сопротивление $\rho=1 / \sigma$ ) и коэффициент Зеебека $\alpha=U_{\mathrm{TEMF}} / \Delta T$ (где $U_{\mathrm{TEMF}}-$ напряжение термоэдс, $\Delta T-$ разница температур между горячим и холодным концами материала):

$$
Z T=\frac{\alpha^{2} \sigma}{\kappa} T
$$

Как правило, эти параметры не являются независимыми друг от друга в одном материале: при увеличении электропроводности наблюдается рост коэффициента теплопроводности за счет увеличения вклада переноса тепла свободными носителями заряда и уменьшение коэффициента Зеебека за счет изменения положения уровня Ферми.

Современные тенденции технологии изготовления термоэлектриков направлены на создание сильно легированных поликристаллических наноматериалов, имеющих такую структуру и такие свойства границ нанозерен, которые обеспечивают низкие значения теплопроводности и одновременно высокие значения коэффициента Зеебека и электропроводности [1-3]. Это в свою очередь позволяет повышать значение термоэлектрической добротности ZT.

В настоящей работе исследованы термоэлектрические преобразователи на основе полупроводникового твердого раствора $\mathrm{Si}_{1-x} \mathrm{Ge}_{x}$. Этот материал является перспективным термоэлектриком для среднего $\left(300-600^{\circ} \mathrm{C}\right)$ диапазона температур и имеет целый ряд конкурентных 
преимуществ: низкую стоимость, высокую доступность, наличие хорошо отработанных методов получения и низкую токсичность. Последнее по сравнению с аналогами является одним из главных преимуществ системы $\mathrm{Si}-\mathrm{Ge}$. Кроме того, существует высокий уровень понимания электронных свойств в объеме $\mathrm{Si}_{1-x} \mathrm{Ge}_{x}$. Разработка и исследование термоэлектрических материалов на основе $\mathrm{Si}_{1-x} \mathrm{Ge}_{x}$ является предметом исследования ряда научных коллективов в России и за рубежом [4-7].

В соответствии с изложенными выше принципами наноструктурирования наиболее перспективным методом получения нанополикристаллов является электроимпульсное плазменное спекание (ЭИПС) порошковых материалов, позволяющее эффективно управлять параметрами поликристаллической наноструктуры [4-6]. Однако, несмотря на значительное развитие этого метода, остается неразрешенным ряд вопросов, связанных с легированием материалов, что особенно актуально в области получения термоэлектриков, для которых сильное легирование является одним из главных условий получения высокого значения параметра ZT [1]. По литературным данным, при изготовлении термоэлектрика $\mathrm{Si}-\mathrm{Ge}$ $n$-типа проводимости основной легирующей примесью является фосфор. В работах [4,5,7-9] с использованием метода ЭИПС продемонстрирована возможность легирования $\mathrm{Si}_{1-x} \mathrm{Ge}_{x}$ фосфором до высоких значений его концентрации $\sim 2$ ат\%.

В настоящей работе мы впервые (среди известных нам литературных источников) предложили и выполнили легирование поликристаллического $\mathrm{Si}_{1-x} \mathrm{Ge}_{x}$ другой примесью V группы - сурьмой. Сурьма, как и фосфор, является донором, но выгодно отличается от него более низкой токсичностью, отсутствием риска воспламенения и, как следствие, значительным упрощением технологии получения термоэлектриков. Особенность предложенного способа легирования заключается в том, что оно проводится непосредственно в процессе изготовления наноматериала - путем добавления мелких частиц легирующей $\mathrm{Sb}$ в исходные порошки из германия и кремния. Цель работы заключается в изучении влияния легирования сурьмой на изменение термоэлектрических свойств поликристаллического наноструктурированного $\mathrm{SiGe}$.

Образцы для исследований изготавливались на основе порошковых материалов $\mathrm{Ge}$ и $\mathrm{Si}$ методом электроимпульсного плазменного спекания. В качестве исходного материала для получения порошков использовались измельченные монокристаллические $\mathrm{Si}$ и Ge. Порошок для спекания изготовливался путем размалывания компонентов, которое осуществлялось в два этапа. На первой стадии мелкие частицы $\mathrm{Ge}, \mathrm{Si}$ и $\mathrm{Sb}$ одновременно размалывались с помощью мельницы на базе вибрационного грохота Fritsch Analysette 3 Pro (нержавеющая сталь), до достижения среднего размера частиц 50-100 мкм. Затем порошок подвергался химической очистке путем травления с последующей тщательной промывкой от остатков травителей. После очистки порошок перемещался в стакан для шаровой мельницы
Fritsch Pulverisette 7. Стакан был герметично изолирован от воздушной среды и заполнялся аргоном. Данная процедура позволила избежать окисления материалов в процессе второго этапа размола порошка. Порошок, помещенный в герметичный стакан, размалывался до достижения размера частиц порошка $\sim 100$ нм. Как и в работе [6], размер зерна контролировался посредством измерений на сканирующем электронном микроскопе.

Полученную порошковую смесь помещали в графитовую пресс-форму и подвергали электроимпульсномy плазменному спеканию на установке DR SINTER SPS-625 model SPS-625 с постоянной скоростью нагрева $50^{\circ} \mathrm{C} /$ мин. Нагревание было ограничено максимальной температурой $1000^{\circ} \mathrm{C}$, во избежание расплавления материалов. Температура спекаемой системы измерялась на наружной стенке пресс-формы пирометром CHINO IR-AH. После спекания образец извлекался из прессформы и разрезался на пластины с размерами (длина/ширина/высота) $10 \times 5 \times 3$ мм (части образца, которые находились в контакте с формой, из дальнейшего рассмотрения исключались). Полученные пластины подвергались механической шлифовке, полировке. На заключительном этапе поверхности образцов очищали путем обработки в ультразвуке и органических растворителях. Детали метода ЭИПС приведены в работе [10].

С применением подобной технологии нами были изготовлены порошки двух составов: $\mathrm{Si}_{0.8} \mathrm{Ge}_{0.2}$ и $\mathrm{Si}_{0.65} \mathrm{Ge}_{0.35}$. Результаты исследований образцов с $x=0.2$ опубликованы в [11], данный состав можно считать „стандартным“ для синтеза термоэлектрических материалов. Недостаток состава $\mathrm{Si}_{0.8} \mathrm{Ge}_{0.2}$ заключается в сильной зависимости коэффициента теплопроводности материала от точности задания концентрации Ge. Задание величины х с ошибкой в сторону уменьшения (например, 19 ат\%), приводит к резкому повышению коэффициента теплопроводности [12]. Повышение содержания Ge до 35 ат\% не приводит к существенному повышению коэффициента теплопроводности твердого раствора [4], но, с другой стороны, значительно смягчает требования к точности задания соотношения компонентов. По этой причине в данной работе исследованы образцы с составом 65 ат\% Si и 35 aт\% Ge $(x=0.35)$.

Концентрация легирующей сурьмы в структурах варьировалась в пределах 0-5 ат\%. Требуемые соотношения компонентов задавались на стадии подготовки порошков путем пересчета требуемых атомных процентов в весовые и подбора соответствующего веса каждого из исходных компонентов.

\section{2. Методы исследования}

Полированная поверхность образцов изучалась методом сканирующей электронной микроскопии на микроскопе Jeol JSM-IT300LV (ЦКП НИИХ). Исследования морфологии поверхности, структуры, размеров 
Параметры полученных искровым спеканием образцов

\begin{tabular}{c|c|c|c|c}
\hline $\begin{array}{c}\text { № } \\
\text { образца }\end{array}$ & $\begin{array}{c}\text { Концентрация Sb } \\
\text { в исходном порошке, ат\% }\end{array}$ & $\begin{array}{c}\text { Тип проводимости } \\
\text { (по знаку } \alpha)\end{array}$ & $\begin{array}{c}\rho, \text { Oм } \cdot \mathrm{M} \\
\left(50-350^{\circ} \mathrm{C}\right)\end{array}$ \\
\hline 1 & 0 & $p$ & $6.8 \cdot 10^{-6}$ & $1.2 \cdot 10^{-2}-1 \cdot 10^{-2}$ \\
2 & 0.5 & $n$ & 0.32 & $4 \cdot 10^{-5}$ \\
3 & 1.0 & $n$ & 0.01 & $4 \cdot 10^{-4}$ \\
4 & 2.0 & $n$ & 0.05 & $2.5 \cdot 10^{-4}$ \\
5 & 5.0 & $n$ & 0.075 & $1.5 \cdot 10^{-4}$
\end{tabular}

зерен и пор были проведены в SE (вторичные, низкоэнергетичные электроны) или BSE (отраженных, обратнорассеянных электронах) режимах. На полученных электронно-микроскопических изображениях были также построены карты распределения элементов по поверхности структур. Измерения выполнены методом рентгеновского энергодисперсионного микроанализа (EDXMA) с использованием приставки $\mathrm{X}-\mathrm{Max}^{\mathrm{N}} 20$ (Oxford Instruments) сканирующего электронного микроскопа. При определении состава и построении карт распределения элементов по поверхности использовались линии $\mathrm{Si} K_{\alpha}$, Ge $K_{\alpha}$, Ge $L_{\alpha}, \mathrm{Sb} L_{\alpha}$. Состав рассчитывался методом фундаментальных параметров, реализованном на базе программного обеспечения системы микроанализа.

Анализ состава выполнялся в трех режимах:

- в режиме картирования (рентгеновский микроанализ);

- в режиме интегрального сбора сигнала с площади от $1 \mathrm{Mм}^{2}$ до $50 \mathrm{мкм}^{2}$;

- в режиме сбора сигнала с малой площади для анализа состава в зернах мелкозернистой структуры.

Термоэлектрические характеристики были измерены для каждой структуры в диапазоне температур 50-350 ${ }^{\circ}$. Выбор такого интервала температур обусловлен тем, что в образцах, легированных выше предела растворимости (<1 ат\% для $\mathrm{Si}$ ), возможна сегрегация сурьмы в крупные кластеры [13]. Эффект наиболее сильно проявляется при температурах нагрева выше $350^{\circ} \mathrm{C}$, а при $T \leq 350^{\circ} \mathrm{C}$ коэффициент сегрегации сурьмы снижается на несколько порядков по сравнению с высокотемпературным значением (до $\approx 10^{2}$ ) [13]. Для измерения электрических и термоэлектрических характеристик на поверхность образцов наносились металлические омические контакты на основе $\mathrm{Au}$.

При измерении коэффициента Зеебека края образцов помещались на две независимые печи. Между концами образцов создавалась постоянная разность температур, равная $10 \mathrm{~K}$; появляющаяся в результате создания разности температур эдс измерялась с помощью вольтметра Keithley 2400. Термоэдс измерялась с помощью золотых зондов, чтобы избежать дополнительного вклада в измеряемое значение за счет термоэдс между материалом контакта и материалом зонда (термоэдс $\mathrm{Au}$ зондов составляет единицы мкВ/К, что позволяет пренебречь их вкладом в результат измерений). Образец электрически изолировался от графитовой печи тонким слоем слюды. Значение коэффициента Зеебека рассчитывалось как

$$
\alpha=\frac{1}{2}\left(\frac{U_{1}}{10 K}+\frac{U_{2}}{-10 K}\right),
$$

где $U_{1}\left(U_{2}\right)$ - величина термоэдс для условно положительной (отрицательной) разницы температур, с учетом знака. За температуру измерений при этом бралось среднее значение между температурами „горячего“ и „холодного“ концов. Измерения проводились в вакууме с давлением остаточных паров около $10^{-3}$ Торр для уменьшения отвода тепла от нагретых областей образца окружающей средой [5].

Температурная зависимость электросопротивления образца измерялась при нулевой разности $\Delta T$ на концах образца. Величина электросопротивления измерялась „стандартным“ четырехзондовым методом. С учетом известных геометрических размеров образца вычислялось удельное сопротивление $\rho$ каждой структуры.

Значение коэффициента теплопроводности определялось методом стационарного теплового потока [14]. Измерение выполнялось с использованием эталонных структур с известным значением $\kappa$. Измеряемый образец помещался между двумя эталонами таким образом, чтобы все материалы находились в плотном тепловом контакте [14]. Между нижним краем нижнего эталона и верхним краем верхнего эталона задавалась постоянная разность температур (т.е. постоянный тепловой поток). Согласно [14], в этом случае изменение значения температуры на границах эталон/образец и образец/эталон зависит от соотношения коэффициентов теплопроводности.

Из измеренных значений коэффициента теплопроводности $\kappa$, удельного сопротивления $\rho=1 / \sigma$ и коэффициента Зеебека $\alpha$ по формуле (1) рассчитывался коэффициент ZT и строилась зависимость ZT от температуры.

\section{3. Результаты эксперимента}

По данным электронографии на отражение все изготовленные образцы $\mathrm{SiGe}$, как нелегированные, так и легированные $\mathrm{Sb}$, имели структуру поликристалла. 

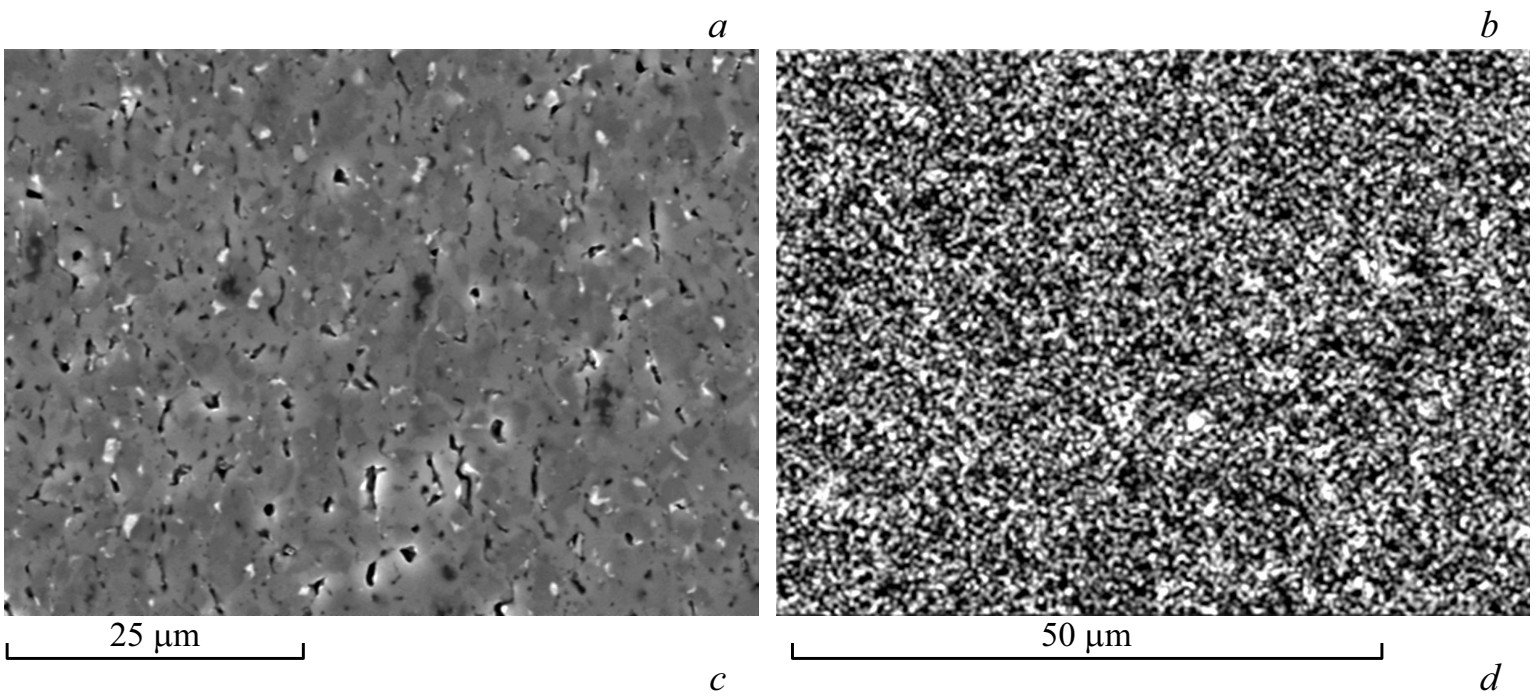

$b$
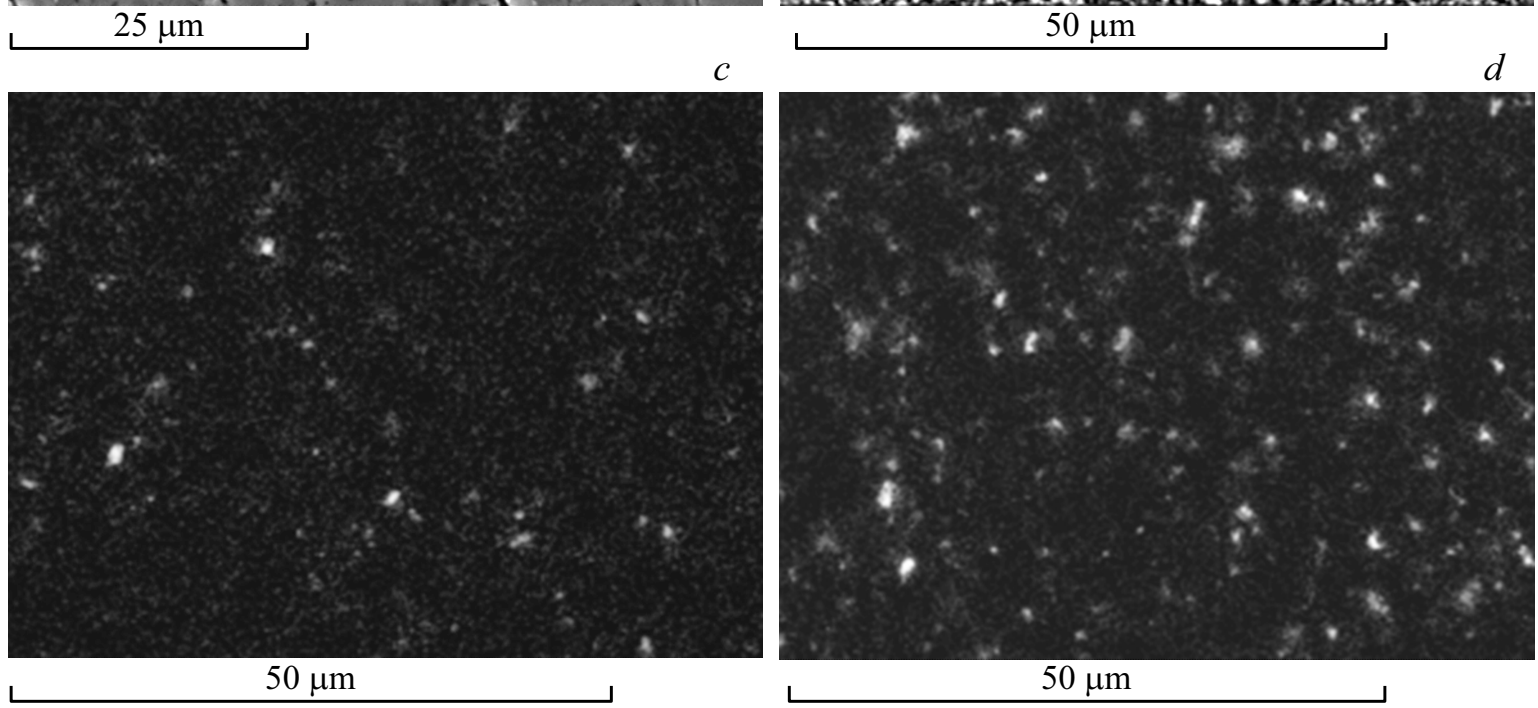

Pис. 1. $a$ - электронно-микроскопическое изображение поверхности структуры $2 ; b$ - карта распределения $\mathrm{Sb}$ по поверхности структуры при уровне легирования 0.5 ат\%; $c$ - карта распределения $\mathrm{Sb}$ по поверхности структуры при уровне легирования 1 ат\% (светлые области соответствуют повышенной концентрации сурьмы); $d$ - карта распределения Sb по поверхности структуры при уровне легирования 2 ат\% (светлые области соответствуют повышенной концентрации сурьмы).

Метод сканирующей электронной микроскопии подтвердил наличие мелкозернистой структуры: средний размер зерен составил $\sim 100$ нм. На рис. $1, a-d$ представлены электронно-микроскопическое изображение поверхности одной из исследованных структур и карты распределения $\mathrm{Sb}$ по поверхности при разном ее содержании в структуре.

В силу идентичности технологических режимов в части спекания, изображения поверхности всех исследованных структур оказались подобны. Различие между образцами заключается лишь в наличии в части из них кластеров $\mathrm{Sb}$, что будет обсуждаться далее. На рис. 1, $a$ представлено электронно-микроскопическое изображение полированной поверхности образца $2 \mathrm{SiGe}$, с наименьшим процентным содержанием сурьмы (см. таблицу).

Видно, что структура состоит из спеченных между собой частиц $\mathrm{Ge}$ и $\mathrm{Si}$, а также пор (небольшая концентрация менее $10 \%$ ). Наличие пор приводит к некоторому понижению коэффициента теплопроводности, что повышает величину ZT (формула 1). Карты распределения элементов $\mathrm{Ge}$ и $\mathrm{Si}$ (на рисунках не представлено) свидетельствуют о наличии перемешивания $\mathrm{Ge}$ и $\mathrm{Si}$, так как сигналы от $\mathrm{Ge}$ и от $\mathrm{Si}$ фиксируются во всех точках поверхности. В то же время перемешивание в выбранном режиме спекания является неполным, поскольку наблюдаются области с локально высоким содержанием $\mathrm{Ge}$ и области с локально высоким содержанием $\mathrm{Si}$.

Остановимся подробнее на картах распределения сурьмы по поверхности образцов (рис. $1, b-d$ ), поскольку концентрация сурьмы являлась единственным варьируемым параметром. Для образца 2, с наименьшим содержанием Sb (0.5 ат\%), зарегистрировано сравнительно однородное распределение атомов $\mathrm{Sb}$ по поверхности (рис. $1, b$ ). Повышение концентрации $\mathrm{Sb}$ до 1 ат\% (образец 3) приводит к появлению на карте областей с локально высоким содержанием $\mathrm{Sb}$ (рис. 1, c). Анализ этих областей в режиме собирания сигнала с малой пло- 

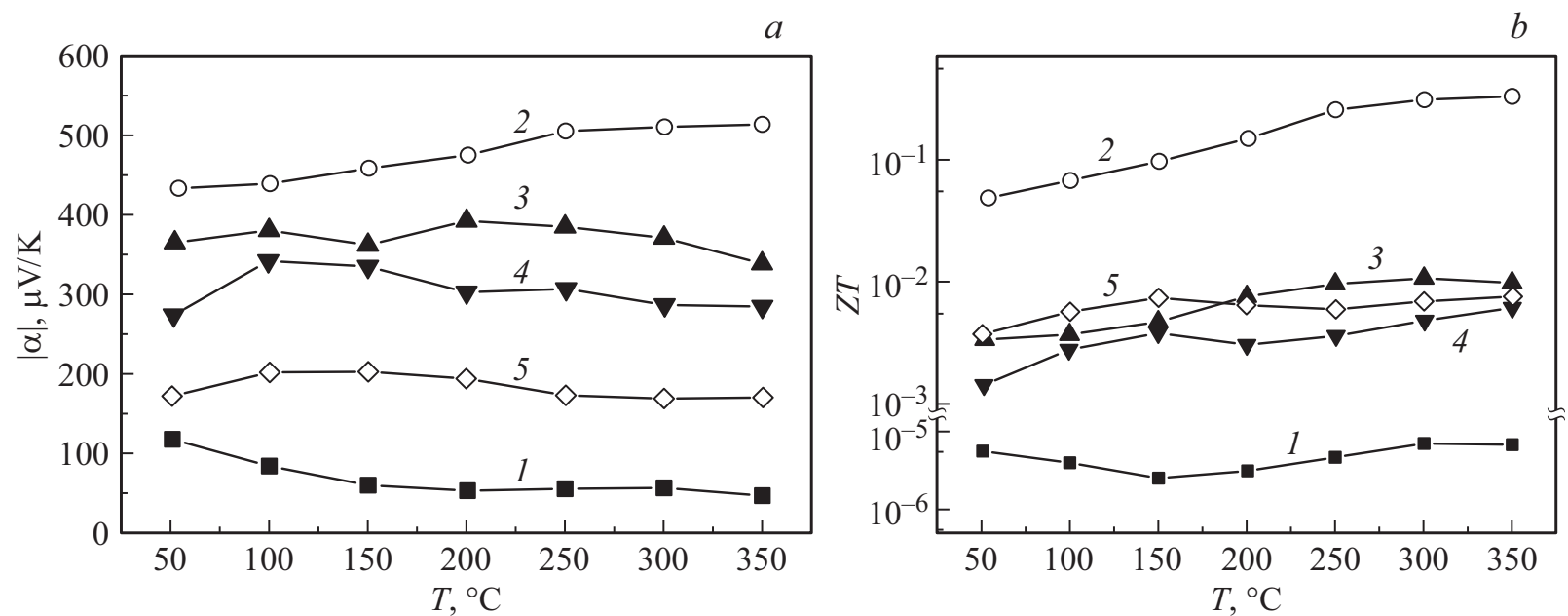

Рис. 2. $a-$ температурные зависимости коэффициента Зеебека, измеренные для образцов $1-5$ (см. таблицу). Номер кривой соответствует номеру образца; $b$ - температурные зависимости коэффициента термоэлектрической добротности, рассчитанные для образцов $1-5$ (см. таблицу). Номер кривой соответствует номеру образца.

щади показал, что они состоят из $\mathrm{Sb}$ с концентрацией, близкой к 100\%. Следовательно, увеличение концентрации $\mathrm{Sb}$ до $1 \mathrm{aT \%}$ привело к появлению кластеров $\mathrm{Sb}$ в матрице $\mathrm{Ge}-\mathrm{Si}$.

Повышение концентрации сурьмы до 2 ат\% (образец 4 , рис. $1, d)$, т. е. в 2 раза по отношению к образцу 3 , приводит к повышению количества кластеров $\mathrm{Sb}$ в 7 раз (ср. рис. $1, c$ и $d$ ), т. е. непропорционально по отношению к изменению концентрации Sb в материале. Дальнейшее повышение содержания $\mathrm{Sb}$ до 5 ат\% (образец 5) также приводит к непропорциональному увеличению концентрации кластеров (в 5 раз по отношению к образцу 4 - не показано). Таким образом, мы обнаружили, по-видимому, предельный уровень легирования нанополикристаллического $\mathrm{Si}_{1-x} \mathrm{Ge}_{x}(x=0.35)$ сурьмой $\leq 1$ ат\%. Введение сурьмы в исходный порошок выше этого значения приводит к формированию кластеров $\mathrm{Sb}$.

Термоэлектрические свойства образцов 1-5 представлены на рис. 2, $a, b$ и таблице. Удельное сопротивление образцов в исследуемом интервале температур практически не изменяется, что свидетельствует о сильном легировании и близком к металлическому характере проводимости. Исключение составляет образец 1, не содержащий $\mathrm{Sb}$ в исходной смеси. Его удельное сопротивление медленно изменяется с температурой от значения $1.2 \cdot 10^{-2} \mathrm{OM} \cdot$ м при $T=50^{\circ} \mathrm{C}$ до $1 \cdot 10^{-2} \mathrm{OM} \cdot \mathrm{M}$ при $T=350^{\circ} \mathrm{C}$ Наименьшее удельное сопротивление характерно для образца 2, содержащего $0.5 \mathrm{aT} \% \mathrm{Sb}$ (см. таблицу). Повышение концентрации $\mathrm{Sb}$ до 1 ат\% приводит к увеличению на порядок величины сопротивления. Дальнейшее повышение концентрации Sb приводит к пропорциональному снижению сопротивления: для образцов с содержанием $\mathrm{Sb} 1,2$ и 5 ат\% среднее значение сопротивления составляет $\sim 4 \cdot 10^{-4}, 2.5 \cdot 10^{-4}$ и $1.5 \cdot 10^{-4}$ Ом $\cdot$ м, соответственно (см. таблицу).
На рис. 2, $а$ представлены температурные зависимости коэффициента Зеебека исследованных образцов. Зависимости имеют подобный вид, величина коэффициента Зеебека слабо меняется с температурой измерений. Знак термоэдс для всех образцов, за исключением образца 1, соответствует электронной проводимости, что связано с легированием материала $\mathrm{Sb}$ - донорной примесью. Наибольшие значения термоэдс характерны для образца 2. По-видимому, формирование кластеров в матрице материала приводит к значительному снижению величины термоэдс, что может быть обусловлено как наличием внутренних потенциальных барьеров на границах металлической $\mathrm{Sb}$ и полупроводникового $\mathrm{Ge}_{x} \mathrm{Si}_{1-x}$, так и вкладом кластеров $\mathrm{Sb}$ в термоэлектрические эффекты. Так, наименьшее для легированного материала значение коэффициента Зеебека характерно для образца 5 с наибольшим содержанием $\mathrm{Sb}$. Для образца 1, не содержащего $\mathrm{Sb}$ в исходном порошке, значение коэффициента Зеебека минимально и уменьшается (по модулю) с температурой измерений. В отличие от легированных образцов, знак термоэдс образца 1 соответствует дырочной проводимости, это может быть связано с тем, что часть исходных материалов содержала акцепторную примесь.

На рис. 2, $b$ представлены температурные зависимости коэффициента термоэлектрической добротности. Наименьшие значения характерны для нелегированного образца, что связано с наибольшими полученными значениями удельного сопротивления и наименьшими значениями коэффициента Зеебека. Легирование образца приводит к значительному увеличению коэффициента ZT, что вполне соответствует известным представлениям о свойствах термоэлектрических материалов. В структуpax с концентрацией $\mathrm{Sb}$ в пределах 1-5aт\% величина коэффициента ZT находится приблизительно на одном уровне и повышается с ростом температуры измерений. 
Наибольшие значения ZT были получены при максимальной температуре $350^{\circ} \mathrm{C}$ и составили $0.01,0.05$ и 0.075 для содержания $\mathrm{Sb} 1,2$ и 5 ат\% соответственно. В структуре с уровнем легирования, равным 0.5 ат\% сурьмы, получена наибольшая величина коэффициента $\mathrm{ZT}$, которая при температуре $350^{\circ} \mathrm{C}$ составила 0.32 .

Перейдем к обсуждению экспериментальных результатов. Зарегистрированные на рис. $1 c, d$ кластеры $\mathrm{Sb}$, по-видимому, обусловлены сегрегацией сурьмы при высокой концентрации $\mathrm{Sb}$ в твердом растворе $\mathrm{Ge}_{x} \mathrm{Si}_{1-x}$. Вероятно, для исследуемой системы в выбранных режимах спекания предел растворимости $\mathrm{Sb}$ ниже $1 \mathrm{aT} \%$. Поэтому для образца 2 с содержанием $\mathrm{Sb} 0.5$ aт\% имеет место однородное легирование, что сопровождается повышением концентрации носителей заряда и снижением электросопротивления. Подобная ситуация оптимальна для получения высокого значения термоэлектрической добротности [1]. Повышение концентрации выше 1 ат\% приводит к принципиальному изменению механизма легирования, в результате которого сурьма может находиться в двух фазовых состояниях: в состоянии замещения атомов $\mathrm{Ge}(\mathrm{Si})$ либо в виде крупного металлического кластера. При этом концентрация атомов замещения значительно понижается, что приводит к повышению сопротивления. Для подобной многофазной системы величина коэффициента ZT значительно ниже, чем для однородно легированного материала. Отметим, что сегрегация $\mathrm{Sb}$ в твердых растворах $\mathrm{GeSi}$ ранее наблюдалась в работах $[15,16]$ для тонкопленочных структур. Для оптимальных условий легирования получено значение коэффициента ZT, равное 0.32 при температуре $350^{\circ} \mathrm{C}$. Данное значение несколько уступает величинам ZT, полученным для аналогичных материалов, легированных атомами фосфора до высокой концентрации $(\mathrm{ZT} \approx 0.45$ в работе [8] и $\mathrm{ZT} \approx 0.4$ в работе [17]). Подчеркнем, что в исследуемой нами системе имеется потенциал для оптимизации свойств за счет варьирования режимов спекания и параметров наноструктуры, а также за счет методов активации примеси, таких, как термический отжиг.

\section{4. Заключение}

Таким образом, в настоящей работе выполнено формирование и исследование термоэлектрических материалов на основе твердых растворов $\mathrm{Ge}_{x} \mathrm{Si}_{1-x}$, легированных атомами $\mathrm{Sb}$ до концентрации в пределах 0-5aт\%. Получено, что при концентрации $\mathrm{Sb}$ ниже 1 aт\% осуществляется эффективное легирование твердого раствора в процессе спекания, которое позволяет получить термоэлектрический материал со сравнительно высоким коэффициентом термоэлектрической добротности. Повышение концентрации сурьмы в диапазоне 1-5ат\% приводит к изменению механизма легирования, результатом которого является повышение сопротивления материалов и коалесценция $\mathrm{Sb}$ в крупные кластеры. Для таких материалов отмечается существенное повышение сопротивления и снижение коэффициента Зеебека, что в соответствии с формулой (1) приводит к снижению коэффициента термоэлектрической добротности.

\section{Финансирование работы}

Работа выполнена при поддержке гранта РНФ (проект 17-79-20173).

\section{Конфликт интересов}

Авторы заявляют, что у них нет конфликта интересов.

\section{Список литературы}

[1] C. Gayner, K.K. Kar. Prog. Mater. Sci., 83, 330 (2016).

[2] CRC Handbook of Thermoelectrics, ed. by D.M. Rowe (CRC Press, N.Y., 1995).

[3] E. Witkoske, X. Wang, M. Lundstrom, V. Askarpour, J. Maassen. J. Appl. Phys., 122, 175102 (2017).

[4] S. Bathula, M. Jayasimhadri, N. Singh, A.K. Srivastava, J. Pulikkotil, A. Dhar, R.C. Budhani. Appl. Phys. Lett., 101, 213902 (2012).

[5] R. Murugasami, P. Vivekanandhan, S. Kumaran, R. Suresh Kumar, T. John Tharakan. Scripta Materialia, 143, 35 (2018).

[6] M.V. Dorokhin, I.V. Erofeeva, Yu.M. Kuznetsov, M.S. Boldin, A.V. Boryakov, A.A. Popov, E.A. Lantsev, N.V. Sakharov, P.B. Demina, A.V. Zdoroveyshchev, V.N. Trushin. Nanosystems-Physics, Chemistry, Mathematics, 9, 622 (2018).

[7] D. Thompson, D. Hitchcock, A. Lahwal, T.M. Tritt. Emerging Mater. Res., 1, 299 (2012).

[8] K. Romanjek, S. Vesin, L. Aixala, Baffie, G. Bernard-Granger, J. Dufourcq. J. Electron. Mater., 44, 2192 (2015).

[9] Z. Zhu, S. Guo. Key Engin. Mater., 703, 70 (2016).

[10] V.N. Chuvil'deev, M.S. Boldin, A.V. Nokhrin, A.A. Popov. Acta Astronautica, 135, 192 (2017).

[11] И.В. Ерофеева, М.В. Дорохин, А.В. Здоровейщев, Ю.М. Кузнецов, А.А. Попов, Е.А. Ланцев, А.В. Боряков, В.Е. Котомина. ФТП, 52 (12), 1455 (2018).

[12] F. Schaffler, M.E. Levinshtein, S.L. Rumyantsev, M.S. Shur. (John Wiley \& Sons, Inc., N.Y., 2001).

[13] D.V. Yurasov, M.N. Drozdov, A.V. Murel, M.V. Shaleev, N.D. Zakharov, A.V. Novikov. J. Appl. Phys., 109, 113533 (2011).

[14] Е.Д. Девяткова, А.В. Петров, И.А. Смирнов. ФТТ, 2, 738 (1960).

[15] М.Н. Дроздов, А.В. Новиков, Д.В. Юрасов. ФТП, 47, 1493 (2013).

[16] Yu.B. Bolkhovityanov, A.S. Deryabin, A.K. Gutakovskii, L.V. Sokolov. J. Cryst. Growth, 297, 57 (2006).

[17] G.H. Zhu, H. Lee, Y.C. Lan, X.W. Wang, G. Joshi, D.Z. Wang, J. Yang, D. Vashaee, H. Guilbert, A. Pillitteri, M.S. Dresselhaus, G. Chen, Z.F. Ren. Phys. Rev. Lett., 102, 196803 (2009).

Редактор Г.А. Оганесян 


\section{In-situ doping of thermoelectric materials based on SiGe solid solutions during their synthesis by spark plasma sintering technique}

M.V. Dorokhin ${ }^{1}$, P.B. Demina ${ }^{1}$, I.V. Erofeev ${ }^{1}$,

A.V. Zdorodeyschev' ${ }^{1}$, Yu.M. Kuznetsov ${ }^{1}$, M.S. Boldin ${ }^{1}$, A.A. Popov' ${ }^{1}$, E.A. Lantsev ${ }^{1}$, A.V. Boryakov ${ }^{2}$

${ }^{2}$ Lobachevsky State University of Nizhny Novgorod, 603950 Nizhny Novgorod, Russia

${ }^{2}$ Sedakov Scientific Research Institute

of Measurement Systems,

Russian Federal Nuclear Center,

603950 Nizhny Novgorod, Russia

Abstract The results of the study of thermoelectric materials fabricated by spark plasma sintering method and based on $0-5$ at $\%$ $\mathrm{Sb}$ doped $\mathrm{Ge}_{x} \mathrm{Si}_{1-x}$ solid solutions are presented. It was found that when the concentration of $\mathrm{Sb}$ is below $1 \mathrm{at} \%$ is an effective doping of the solid solution occurs during the sintering process, which allows one to obtain a thermoelectric material with a relatively high thermoelectric figure of merit. An increase in the concentration of antimony in the range of $1-5$ at $\%$ leads to a change in the mechanism of doping, the result of which is an increase in the resistance of materials and the segregation of $\mathrm{Sb}$ into large clusters. For such materials, a significant decrease in the Seebeck coefficient and $\mathrm{ZT}$ value were revealed. The highest obtained thermoelectric figure of merit $(\mathrm{ZT})$ for $\mathrm{Sb}$ doped $\mathrm{GeSi}$ was 0.32 at $350^{\circ} \mathrm{C}$, which is comparable with the known analogues for the $\mathrm{Ge}_{x} \mathrm{Si}_{1-x}$ solid solution. 